\title{
Abordaje de la fibrosis quística desde la consulta de enfermería. Caso clínico
}

\author{
ELENA BACHERo CASTILLEJo \\ al316173@uji.es \\ Águeda Cervera Gasch \\ cerveraa@uji.es
}

\section{Resumen}

Introducción: La fibrosis quística es una enfermedad multisistémica de origen genético debido a la mutación en el gen que codifica la «proteína reguladora de la conductancia transmembrana de la fibrosis quística». La alteración de este gen conlleva un defecto en el transporte de electrolitos a través de las membranas celulares que se traduce en una alteración en diversos sistemas del cuerpo. Método: Se escoge un niño que padece esta enfermedad para seguir su evolución y poder realizar un plan de intervención de enfermería para poder mejorar su calidad de vida. Se lleva a cabo el seguimiento del paciente en sus visitas a la pediatra, puesto que el paciente escogido es un niño de 7 meses. En las visitas al centro de salud, el paciente es visitado por la enfermera de pediatría y por la pediatra siguiendo el programa del niño sano. Resultados: Lo importante son las revisiones del niño y proceder ante cualquier problema. Se trata de una enfermedad en la que no se puede realizar una prevención primaria, por lo que los cuidados de enfermería se llevan a cabo para evitar que aparezcan complicaciones. Conclusión: Es fundamental una buena coordinación entre el equipo de atención primaria y la familia, con el fin de ofrecer unos cuidados de calidad.

Palabras clave: fibrosis quística, plan de intervención, programa del niño sano, cuidados de enfermería, atención primaria y calidad de vida.

\section{Abstract}

Introduction: Cystic fibrosis is a multisystemic disease of genetic origin due to a mutation in the gene that codifies the "regulatory protein of the conductance transmembrane of cystic fibrosis". Alteration of this gene leads to a fault in transporting electrolytes across the cellular membranes, which produces an alteration in diverse body systems. Method: A male child with cystic fibrosis was selected to follow his evolution and to plan the nursing intervention to improve his quality of life. The patient's follow-up was carried out during visits to the paediatrician since the selected patient was a 7-month-old child. During visits to the health centre, the patient was visited by the paediatric nurse and by the paediatrician, following the programme of a healthy child. Results: The child's check-ups and proceeding to deal with any prob- 
lem are the main points. As primary prevention with this disease is not possible, nursing care is carried out prevent complications from appearing. Conclusion: Good coordination is fundamental between the primary healthcare team and the family in order to offer quality care.

Keywords: Cystic fibrosis, intervention plan, programme of healthy children, nursing care, primary healthcare and quality of life.

\section{Introducción}

La fibrosis quística una enfermedad multisistémica, de origen genético debido a la mutación en el gen que codifica la «proteína reguladora de la conductancia transmembrana de la FQ» (Barrio, García y Gartner, 2009). La alteración de este gen conlleva un defecto en el transporte de electrolitos a través de las membranas celulares. Esto se traduce en una alteración en diversos sistemas del cuerpo, como los pulmones, el páncreas, el sistema urogenital, el esqueleto y la piel; casa la enfermedad pulmonar obstructiva crónica, infecciones pulmonares, la producción deficiente de enzimas pancreáticos, la osteoporosis y la elevada concentración de electrolitos en el sudor (Bradley y cols., 2015; Nicholson, 2013).

La fibrosis quística está producida por mutaciones en el gen que codifica el regulador de la conductancia transmenbrana de la fibrosis quística (CFTR). El CFTR actúa como canal de cloro y se encuentra en todos los tejidos exocrinos; el defecto en el transporte del ion cloro causa que estos pacientes tengan un sudor salado y conduce a una deshidratación de las secreciones del tracto respiratorio, pancreáticas, hepáticas, intestinales y genitourinarias, aumentando su viscosidad. Además, la alteración del CFTR da lugar a un aumento de la reabsorción de sodio y cloro que está acompañado de una reabsorción pasiva de agua y produce deshidratación de la superficie del epitelio ciliado respiratorio, lo que impide el correcto deslizamiento del moco a través del árbol traqueobraquial, lo que conlleva al estancamiento del moco que servirá como cultivo para diversos microorganismos (Bradley y cols., 2015; Hoen y cols., 2015).

Otro factor patogénico es la respuesta inflamatoria exagerada, causada por la infección y por la alteración presente en el epitelio bronquial y que se manifiesta por un intenso infiltrado de neutrófilos, los cuales dañarán más el tejido bronquial a causa de la secreción de proteasas. Además, el cúmulo de ADN, liberado por la lisis de neutrófilos, incrementa la densidad y la viscosidad de las secreciones. Las alteraciones de las secreciones respiratorias determinan una predisposición para la colonización-infección broncopulmonar crónica. En esta infección broncopulmonar pueden estar implicados diferentes microorganismos, entre ellos: Pseudomonas aeruginosa, Staphylococcus aureus, Haemophilius influenzae, Streptococcus pneumoniae, etc. Los pacientes que son colonizados por Pseudomonas aeruginosa tienen un mayor riesgo de mortalidad durante los primeros 5 años de vida (Barrio Gómez de Agüero y cols., 2009).

El primer microorganismo reconocido como causante de la infección pulmonar crónica en estos pacientes es el Staphylococcus aureus. Este microorganismo escapa de manera más eficiente de los fagosomas de las células del epitelio bronquial deficientes en la CFTR. Además, se desarrollan de manera adecuada en los medios con alta osmolaridad, situación que se produce en las vías respiratorias del paciente con FQ. 
El microorganismo Haemophilius influenzae puede colonizar hasta el $30 \%$ de los pacientes con $\mathrm{FQ}$, con mayor incidencia en los niños de menor edad. La vacuna conjugada contra $\mathrm{H}$. influenzae tipo b no tendría utilidad en la prevención de la colonización. Streptococcus pneumoniae se comportaría como S. aureus, capaz de adherirse a la superficie mucosa, lo que favorece las infecciones broncopulmonares. Además, es capaz de elaborar productos extracelulares que estimulan la secreción mucosa y contribuyen a una peor evolución de las exacerbaciones. Por otra parte, forma biopelículas, lo que facilita su permanencia en el árbol bronquial.

Además de todas las complicaciones que puede ocasionar la infección broncopulmonar, también puede haber complicaciones en otros órganos del cuerpo, ya que la fibrosis quística afecta a todo el cuerpo. Uno de los órganos afectados es el páncreas, en el que la producción de enzimas se ve afectada lo que conlleva una mala producción de enzimas (Gammon y cols., 2014).

\section{Método}

Se escoge un niño que padece esta enfermedad para seguir su evolución y poder realizar un plan de intervención de enfermería para poder mejorar su calidad de vida. El niño escogido es un niño de siete meses cuya vida va a estar marcada por su problema crónico de salud. Este niño ha sido escogido ya que padece una enfermedad poco común y que se detecta en los primeros días de vida gracias a las nuevas tecnologías.

La enfermedad que padece este niño se detecta gracias al cribado de metabolopatías congénitas, prueba del talón, que se realiza a las 48 horas del nacimiento de bebé. Con esta prueba se pueden detectar cuatro enfermedades: el hipotiroidismo congénito, la fenilfetonúria, la fibrosis quística y la anemia de células falciformes. La enfermedad que padece este niño es la fibrosis quística.

Antes de realizar cualquier intervención, se tienen que llevar a cabo unos procesos. El primero sería una valoración del paciente y de todo lo que le rodea, teniendo en cuenta a su familia, el trabajo de sus padres, la vivienda, etc. Además, se buscan los recursos con los que cuenta la familia y los factores de riesgo que pueden generar problemas de salud.

Después de esta valoración se tiene que llevar a cabo un diagnóstico, que es la conclusión de la valoración. Se identifican los recursos esenciales para llevar a cabo los cuidados del paciente.

\section{DIAGNÓSTICOS NANDA:}

00084. CONDUCTAS GENERADORAS DE SALUD (ESPECIFICAR): Búsqueda activa de formas de modificar los hábitos sanitarios personales o en el entorno para alcanzar un nivel mas alto de salud. Al acabar el diagnóstico, continuaríamos con la planificación de las actividades para, en este caso, minimizar los problemas de salud, teniendo en cuenta las prioridades de los problemas que se vayan desarrollan para mantener la salud del paciente.

INTERVENCIONES NIC:

8274. FOMENTO DESARROLLO: NIÑO: Facilitar o enseñar a los pacientes/cuidadores a conseguir un crecimiento global y especifico lingüístico, cognitivo, social, emocional y motor, total de niños en edad preescolar y escolar.

6530. MANEJO DE INMUNIZACIÓN/VACUNACIÓN: Control del estado de inmunización, facilitando el acceso a las inmunizaciones y suministro de vacunas para evitar enfermedades contagiosas.

5626. ENSEÑANZA: NUTRICIÓN INFANTIL: Enseñanza de las practicas de nutrición y alimentación durante el primer año de vida. 
Por ultimo, se llevarían a cabo las intervenciones y se evaluarían, es decir, se pondrían en marcha los cuidados que se han decidido en la etapa anterior y, después de comparar las respuestas del paciente, se vería si ha logrado los objetivos y si ha mejorado su estado de salud.

En este paciente, como es un lactante, se tiene que tener en cuenta la situación de los padres, es decir, sus recursos económicos, si tienen trabajo, si están separados, si hay algún familiar que pueda hacerse cargo del niño en caso de que los padres no puedan y que ese familiar tenga las capacidades para realizar las actividades para mejorar la salud del niño, si poseen un vehículo para desplazarse en caso de que fuese necesario, el tipo de vivienda en el que residen, las capacidades de los padres para entender la enfermedad a la que se expone su hijo, etc.

\section{Resultados}

Ante esta enfermedad no se puede hacer gran cosa para prevenir, solo esperar a que aparezcan las complicaciones para poder hacerles frente.

\section{Plan de intervención}

El paciente, al ser un lactante de 7 meses, tiene que ir a la visita con la enfermera de pediatría. En la visita se lleva a cabo un control de la somatometría, como se ha explicado anteriormente.

Se toma el perímetro cefálico, con una cinta métrica especial, que se sitúa por las partes más anchas de la cabeza del niño y por encima de las orejas. Además, se le pesa, en una báscula, dejando al niño solamente con el bodi; y, por último, se toma la talla con un medidor en el que se tumba al niño encima y se estira para que esté correctamente estirado.

Además, como el lactante tiene más de seis meses, se le administra la vacuna de la gripe por ser niño de riesgo. La vacuna no se puede poner antes de los seis y, como a los seis se le han puesto las vacunas del calendario vacunal, es recomendable dejar un mes de diferencia entre las vacunas; de ese modo, se aprovecha la visita de los siete meses a la enfermera de pediatría para administrar la vacuna. Además, se tiene que tener en cuenta que, como tiene menos de 36 meses, solo se administra media dosis.

Al ser el primer año que se le administra la vacuna de la gripe, tiene que volver al mes a la enfermera de pediatría para administrar la segunda dosis que, como anteriormente se ha dicho, solo será media dosis. Así mismo, en la visita de los siete meses, se le pregunta a la madre por la alimentación del niño, es decir, qué es lo que ya come, ya que tiene que estar dejando de tomar solo biberón desde los cinco meses. A los siete meses, el niño tiene que estar comiendo una papilla de cereales con gluten, una papilla de frutas completa y papilla de pollo y verduras. Además, tiene que haber dejado la leche de inicio $(\mathrm{I})$ y haber pasado a la leche de continuación (II).

En la visita de los siete meses, después de haber preguntado por la alimentación que está tomando el niño, se pasa a la alimentación que tiene que introducir, que son las papillas de otras carnes como ternera, cordero y cerdo. Se le explica que tiene que ser del mismo modo que las frutas: ir dando las diferentes carnes por separado y con varios días de intervalo, para poder observar si es alérgico a algún alimento. 


\section{Discusión y conclusiones}

La fibrosis quística es la enfermedad autosómica recesiva grave más frecuente de la población. El aumento de la supervivencia de los pacientes con fibrosis quística se debe a la disponibilidad de los tratamientos de la enfermedad pulmonar, en especial de las infecciones respiratorias.

La FQ puede afectar a los aparatos respiratorio, digestivo y reproductor, como se ha explicado anteriormente. La supervivencia de los pacientes con FQ ha aumentando mucho en las últimas décadas, cuando hace cuarenta años era una enfermedad letal en la infancia. Diversos autores (Barrio y cols., 2009; Nicholson, 2013) indican que actualmente la expectativa de vida media de los pacientes con esta enfermedad se encuentra en torno a los 33 años.

En los niños, sobre todo con este tipo de enfermedad, es muy importante el control del peso y de la talla, ya que bajo peso puede desembocar en complicaciones sobre la enfermedad que padece el niño. Además, se puede ir recomendando a la madre del niño, a lo largo de todas las visitas, como anteriormente se ha dicho, que acuda a un fisioterapeuta especial para niños, para realizar ejercicios fisioterapéuticos pulmonares, para permeabilizar la vía aérea, lograr una buena ventilación y controlar la obstrucción pulmonar. De este modo se pueden prevenir complicaciones que pueden aparecer a lo largo de los años.

Así mismo, se pone a disposición de la familia una consulta con un psicólogo, por si en algún momento necesitan acudir a uno para resolver cualquier problema que puedan tener o que pueda surgir. También se puede acudir al psicólogo para mejorar el clima familiar y adoptar una postura de sobreprotección hacia el niño, ya que un buen clima familiar ayuda a un mejor desarrollo del niño.

Es muy importante una buena coordinación entre el equipo interdisciplinar para poder garantizar una buena calidad de vida para el niño y para su familia. En la Revista Interamericana de Psicología se estudió la relación entre la adherencia al tratamiento, el clima familiar y los estilos educativos. El objetivo de este estudio era investigar si existía relación entre el clima familiar, los estilos educativos y la adherencia al tratamiento en pacientes con FQ, además de investigar si los diferentes grados de afectación de la FQ influyen en el clima familiar. Se obtuvo la participación de 76 pacientes con FQ y sus padres. Las variables evaluadas fueron: el grado de afectación de la FQ, los estilos educativos, el clima familiar y la adherencia al tratamiento. La adherencia al tratamiento fue evaluada a partir de la percepción subjetiva de los pacientes y sus padres.

Los resultados indican que no existe relación entre el clima familiar y la adherencia al tratamiento. Sin embargo, la adopción por parte de los padres de estilos educativos de sobreprotección está relacionada con menores niveles de adherencia. Además, los resultados indican que no hay relación entre el grado de afectación y las variables familiares (Adde, Alvarez, Barbisan y Guimarães, 2013). Aunque no exista relación entre el clima familiar y la adherencia al tratamiento, es necesario instruir a los padres para que adopten estilos educativos no sobreprotectores, para que ayuden a los pacientes y así conseguir que mantengan el tratamiento.

La FQ es una enfermedad de interés científico ya que, como se puede observar en los datos, es una enfermedad de gran incidencia; por tanto, si se investiga constantemente se puede conseguir un tratamiento más eficaz y aumentar más la expectativa de vida de los pacientes, además de aumentar su calidad de vida (Bradley y cols., 2015; Gammon y cols., 2014) 


\section{Referencias bibliográficas}

Adde, F. V., Alvarez, A. E., Barbisan, B. N. y Guimarães, B. R. (2013). Recommendations for long-term home oxygen therapy in children and adolescents. Jornal De Pediatria, 89, 6-17. http://doi.org/10.1016/j.jped.2013.02.003

Barrio, M. I., García, G. y Gartner, S. (2009). Protocolo de diagnóstico y seguimiento de los pacientes con fibrosis quística. Anales de Pediatría, 71, 250-264. http://doi.org/10.1016/j. anpedi.2009.06.020

Bradley, J., O’Neill, B., Kent, L., Hulzebos, E. H. J., Arets, B., Hebestreit, H. y cols. (2015). Exercise Working Group European CF Society (2015). Physical activity assessment in cystic fibrosis: A position statement. Journal of Cystic Fibrosis: Official Journal of the European Cystic Fibrosis Society, 14, 25-32. http://doi.org/10.1016/j.jcf.2015.05.011

Gammon, S. T., Foje, N., Brewer, E. M., Owers, E., Downs, C. A., Budde, M. D. y cols. (2014). Preclinical anatomical, molecular, and functional imaging of the lung with multiple modalities. American Journal of Physiology. Lung Cellular and Molecular Physiology, 306, L897-914. http://doi.org/10.1152/ajplung.00007.2014

Hoen, A. G., Li, J., Moulton, L. A., O’Toole, G. A., Housman, M. L., Koestler, D. C. Madan, J. C. y cols. (2015). Associations between Gut Microbial Colonization in Early Life and Respiratory Outcomes in Cystic Fibrosis. The Journal of Pediatrics, 167, 138-147.e3. http:// doi.org/10.1016/j.jpeds.2015.02.049

Nicholson, K. N. (2013). Screening for cystic fibrosis: what every NP should know. The Nurse Practitioner, 38, 32-33. http://doi.org/10.1097/01.NPR.0000433073.84279.48 